www.jmscr.igmpublication.org

Impact Factor (SJIF): 6.379

Index Copernicus Value: 71.58

ISSN (e)-2347-176x ISSN (p) 2455-0450

crossrefDOI: https://dx.doi.org/10.18535/jmscr/v6i7.67

Journal Of Medical Science And Clinical Research

\title{
Laparoscopy in Large Size GIST with Review of Literature
}

\author{
Authors \\ Priyanka Tiwari, Rashmi Pyasi, Shashank Rastogi, Bijendra Sinha, Ajay Kriplani \\ Department of Minimal Access Bariatric Gastro Intestinal Surgery \\ Fortis Memorial Research Institute Gurugram
}

\begin{abstract}
Introduction: In the present study investigated the laparoscopic management of gastric GIST in various locations in stomach.

Method: This study was retrospective review of all GIST patients admitted between Oct2015-Jan 2018 in our institute Fortis Memorial Research Institute were analysed. Patients demographics, clinical presentation, tumour characteristics, radiological, pathological and immunohistochemical findings, techniques of laparoscopic resection, recurrence, postoperative outcome were analysed.

Result: Total 18 patients were taken for laparoscopic excision of GIST tumor of these 16 patients were excised laparoscopically and 2 converted to open partial gastrectomy. In total of 16 patients, 13 patients resected laparoscopically and 3 patients were converted to open.

Conclusion: GIST larger than $5 \mathrm{~cm}$ should not be contraindication for laparoscopic resection but may require open surgery.
\end{abstract}

\section{Introduction}

GIST is the most common mesenchymal tumor of gastrointestinal tract and its incidence is 0.1 to $3 \%$ of gastrointestinal malignancies. The term GIST was coined by Mazur and Clark in 1983.This tumor equally distributed between the men and women. Median age of diagnosis is 60 year (range 40-80 yr.). GIST most commonly present in stomach (60\%-70\%) and more rarely outside the GI tract, including the mesentry, omentum and retroperioneum . Most common presentation of GIST is Gastrointestinal bleeding, followed by abdominal pain, anaemia, palpable mass. Dysphagia, obstruction and weight loss. However, a significant number are discovered incidentally on imaging performed for other reasons.

\section{Patients and Methods}

The aim of our study is to know the feasibility of laparoscopy in large size GIST in various location in stomach and postoperative outcome. The present study was retrospective study in which we analysed all the patients admitted for gastric GIST surgery, irrespective of tumor location and size from Oct 2015-Jan 2018. In this study duration, total 18 patients were taken for laparoscopic excision of gastric GIST, of which 2 patients converted to open surgery. CECT abdomen was done in GIST patients to know the tumor location and growth pattern. Different laparoscopic approaches in treatment of gastric gastrointestinal GIST tumor were done, laparoscopic sleeve gastrectomy, lap wedge resection and lap partial gastrectomy. In laparoscopic excision, after 
creating the pneumoperitoneum, standard ports were placed $(2,10 \mathrm{~mm}$, supraumbilical, epigastric. $3,5 \mathrm{~mm}$, right and left lateral to rectus and one left anterior axillary line. Greater curvature of stomach mobilized and short gastric vessels were divided with harmonic, than GE junction was mobilized for the localization of tumor. Excision of tumor done with $60 \mathrm{~mm}$ endostapler with $2 \mathrm{~cm}$ negative tumor resection margin. Excised tumor sent for HPE and immunohistochemistry. Pathological findings were confirmed to know the GIST and differentiate the GIST from other mesenchymal tumor. GIST diagnosis confirmed by immunohistochemistry and risk stratification was done based on mitotic rate/hpf and $\mathrm{Ki}-67$ proliferation index Intraoperative in all the patients' methylene blue test was done to know the leak. All the patients were also analysed to know the mean surgical duration, mean duration of hospital stay, and postoperative complications, as anastomotic leak, delayed gastric emptying and GE reflux.

\section{Results}

In our study 18 patients of GIST were analysed from Oct 2015- Jan 2018. Mean age was 57.40 years (range 28-83). In total 18 patients, 13 were male and 5 were female. In all the patients most common presentation was melena (8/18 ) $44.44 \%$, abdominal pain (7/18) $38.88 \%$, anaemia ( 6/18) $33.33 \%$, haemetemiasis (6/18) $33.33 \%$.Patients were also present with weakness with jaundice (2/18) $11.11 \%$, cholelithiasis (2/18) $11.11 \%$, loss of appetite (8/18) $44.44 \%$, loss of weight (4/18) $22.22 \%$, In 4 patients, GIST also presented as incidental finding in CECT examination . (table1) In all the cases tumor size was calculated on the basis of CECT findings. and mean tumor size was $8.84 \mathrm{~cm}$ (range $3.5-13.8 \mathrm{~cm}$ ). The most common location was fundus (posteriorly) (7/18) 38.88\%, greater curvature of stomach (4/18) $22.22 \%$, and body of stomach (3/18) $16.66 \%$. It may also occur near the gastroesophageal Junction (2/18) $11.11 \%$, lessor curvature (1/18) 5.55\%, and fundus anteriorly (1/18) $5.55 \%$. (table 2). On the basis of
CECT and endoscopic findings we concluded that, (7/18) patients had exophytic growth pattern, $(6 / 18)$ patient had endophytic growth pattern and (5/18) exoendophytic growth pattern was detected (table 3). Laparoscopic surgery was attempted in total 16 patients out of 6 patients laparoscopic sleeve gastrectomy was done, 4 patients laparoscopic wedge resection, and 3 patients laparoscopic partial gastrectomy was done (table 4). In 3 cases laparoscopic surgery converted to open and the cause for conversion was large size GE junction tumor adherent to adjacent structure. Laparoscopic excision can be done successfully even in large size tumor $(11.5 \times 8.5 \times 7.5 \mathrm{~cm})$, located in posterior wall of fundus of stomach. Decision to open resection for GIST tumor depend upon the CECT finding.

Mean surgical duration $167.9 \mathrm{~min}$ (lap/open) (131/222min) (Table5). Intraoperative, methylene blue dye test was negative in all the cases and postoperatively, gastrograffin study was also done to know the leak before stating orally liquid diet. Thus liquid diet was started 3-5 days. Delayed gastric emptying and GE reflux occur in one case that was managed conservatively (table6). On immunohistochemistry, CD 117, CD 34 positive in $16 / 18$. DOG1 was positive in $2 / 18$ cases, Vimentin positive in $13 / 18$ cases and $S-100$ positivity was present in $11 / 18$ cases (table7). Patients risk stratification was done on the basis of Ki proliferation index. In $14 / 18$ cases $<10$, and 2/18 cases $>10$ (table8).

$4 / 18$ cases confirmed high risk stratification on the basis of mitosis /hpf and Ki proliferation index irrespective of tumor size. In all cases $2 \mathrm{~cm}$ resection margin was negative. In our case series, recurrence was occurred in 2 cases in which $\mathrm{Ki}$ proliferation index $>10$, and $>10$ MITOSIS $/ \mathrm{HPF}$ even after Ro resection. (table 9 ) 
Table 1: Showed demographic characteristics and presenting symptoms

\begin{tabular}{|l|c|}
\hline Characteristic & $\mathbf{n = 1 8}(\mathbf{n \%})$ \\
\hline Mean Age & $57.40(28-83)$ \\
\hline Gender ( Male /Female ) & $13 / 5$ \\
\hline Presenting symptoms & \\
\hline Anemia & $6 / 18(33.33 \%)$ \\
\hline Malena & $8 / 18(44.44 \%)$ \\
\hline Haemetemiasis & $6 / 18(33.33 \%)$ \\
\hline Abdominal Pain & $7 / 18(38.88 \%)$ \\
\hline Weakness with Jaundice & $2 / 18(11.11 \%)$ \\
\hline Cholelithiasis & $2 / 18(11.11 \%)$ \\
\hline Loss of Appetite & $8 / 18(44.44 \%)$ \\
\hline Loss of weight & $4 / 18(22.22 \%)$ \\
\hline Incidental finding & $4 / 18(22.22 \%)$ \\
\hline
\end{tabular}

Table 2: Showed size and location of gastric GIST

\begin{tabular}{|l|c|}
\hline Peoperative GIST Diagnosis & \\
\hline Tumor size ( range ) cm & $8.84(3.5-13.8)$ \\
\hline Tumor location, n (\%) & \\
\hline 1. GE Junction & $2(11.11)$ \\
\hline 2. Lesser Curvature & $1(5.55)$ \\
\hline 3. Fundus ( Posteriorly) & $7(38.88)$ \\
\hline 4. Fundus ( Anteriorly ) & $1(5.55)$ \\
\hline 5.Greater curvature of stomach & $4(22.22)$ \\
\hline 6.Body of stomach & $3(16.66)$ \\
\hline
\end{tabular}

Table 3 Growth pattern of GIST on the basis of CECT finding

\begin{tabular}{|l|c|}
\hline Growth pattern & $\mathbf{n = 1 8}$ \\
\hline 1. Exophytic & 7 \\
\hline 2.Exo-endophytic & 5 \\
\hline 3.Endophytic & 6 \\
\hline
\end{tabular}

Table 4: Laparoscopic Approaches in Treatment of Gastric Gastrointestinal Tumors

\begin{tabular}{|l|c|}
\hline Intraoperative tumor rupture, $\mathbf{n}(\boldsymbol{\%})$ & Nil \\
\hline Conversion to open surgery, $\mathrm{n}(\%)$ & $3(30 \%)$ \\
\hline Median surgical duration (range), min & a \\
\hline Methylene Blue dye leak test & $167.9(\mathrm{~L} / \mathrm{O} 131 / 222)$ \\
\hline
\end{tabular}


Table 5: Intraoperative findings during resection of GIST

\begin{tabular}{|c|c|c|c|c|}
$\begin{array}{c}\text { Laparoscopic } \\
\text { sleeve gastrectomy }\end{array}$ & $\begin{array}{c}\text { Laparoscopic } \\
\text { Wedge resection }\end{array}$ & $\begin{array}{c}\text { Laparoscopic } \\
\text { partial } \\
\text { Gastrectomy }\end{array}$ & $\begin{array}{c}\text { Lap } \\
\text { converted to } \\
\text { open }\end{array}$ & $\begin{array}{c}\text { Open Partial } \\
\text { Gastrectomy }\end{array}$ \\
\hline 6 & 4 & 3 & 3 & 2 \\
\hline
\end{tabular}

Table 6 : Postoperative findings after GIST Resection

\begin{tabular}{|c|c|}
\hline Mean time to tolerate a fluid diet (range), days ${ }^{a}$ & $3.6(2-6)$ \\
\hline Median length of post-operative hospital stay (range), days & $5.6(4-9)$ \\
\hline Complications, n (\%) & $1 / 10$ \\
\hline Anastomotic bleeding, $\mathrm{n}(\%)$ & $0 \%$ \\
\hline $\begin{array}{l}\text { Delayed gastric emptying, } \\
\text { GE Reflux }\end{array}$ & $1 / 10$ \\
\hline
\end{tabular}

Table 7: Distribution of immunohistochemical markers in GIST

\begin{tabular}{|c|c|}
\hline Positive for & $\mathbf{n}=\mathbf{1 8}$ \\
\hline CD117 & 16 \\
\hline DOG1 & 2 \\
\hline CD34 & 16 \\
\hline S-100 & 11 \\
\hline Vimentin & 13 \\
\hline
\end{tabular}

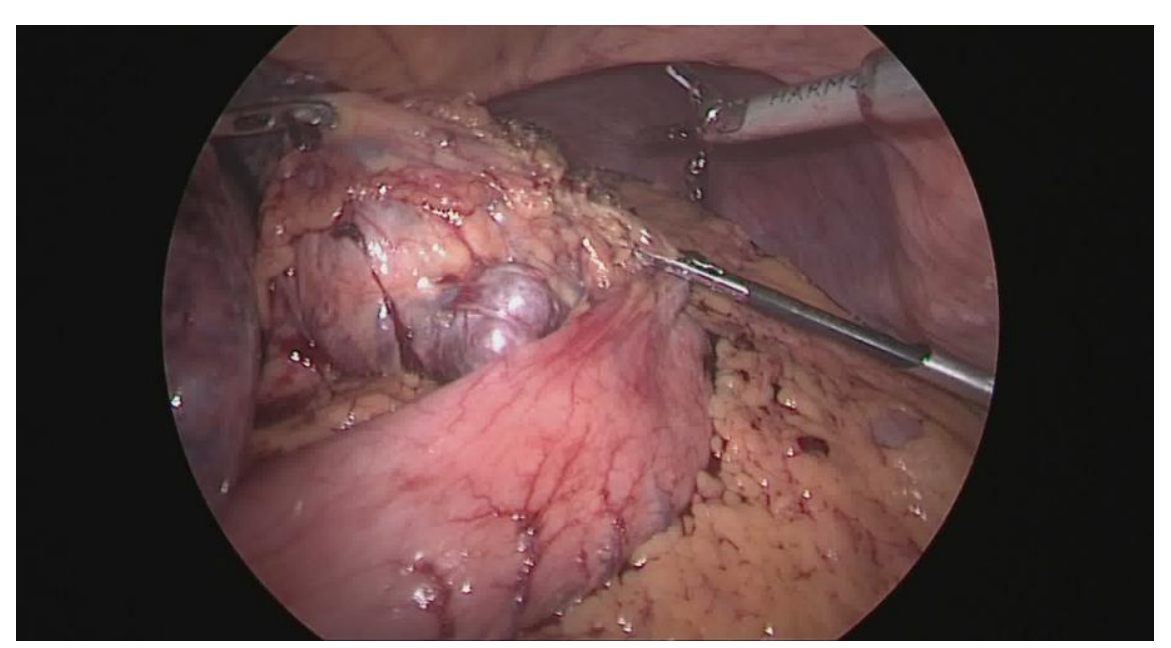

Fig 1: Showed GIST at GE Junction 


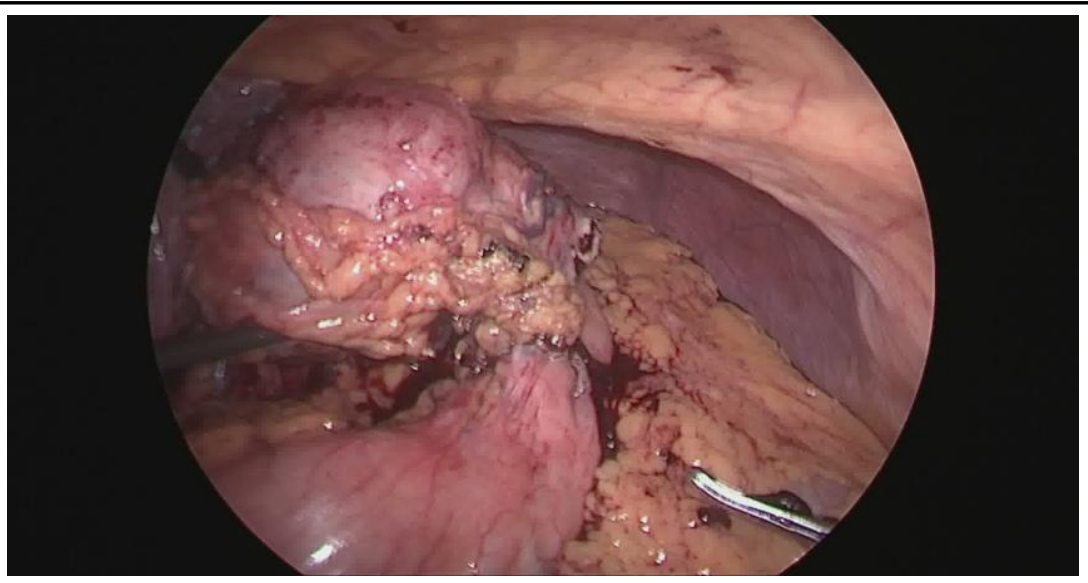

Fig 2: Showed GIST at lessor curvature

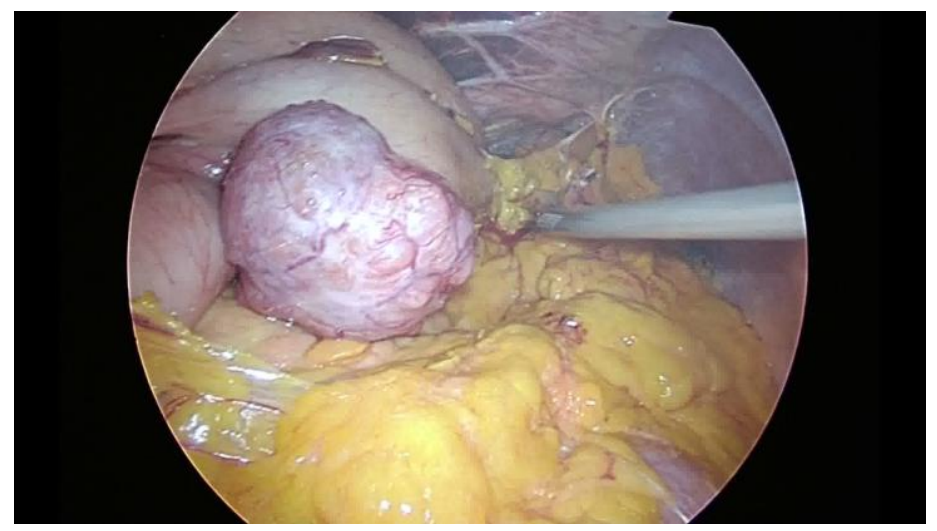

Fig 3: Showed GIST at posterior wall of stomach

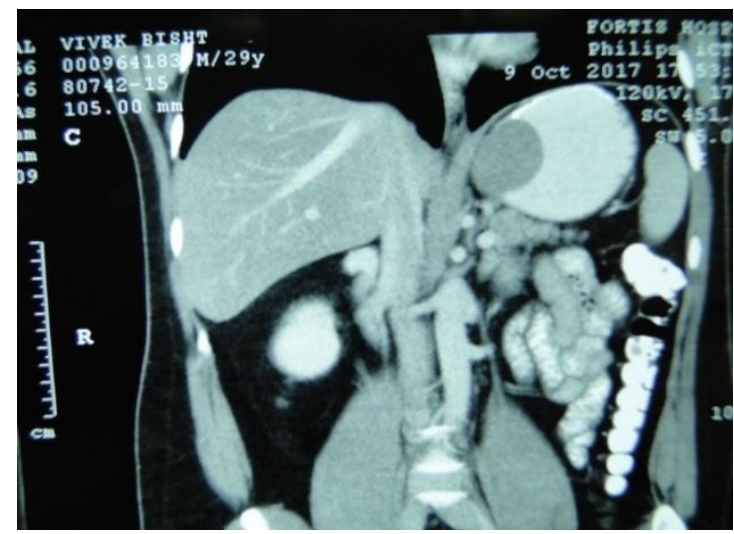

Fig 4: CECT finding of Gastric GIST

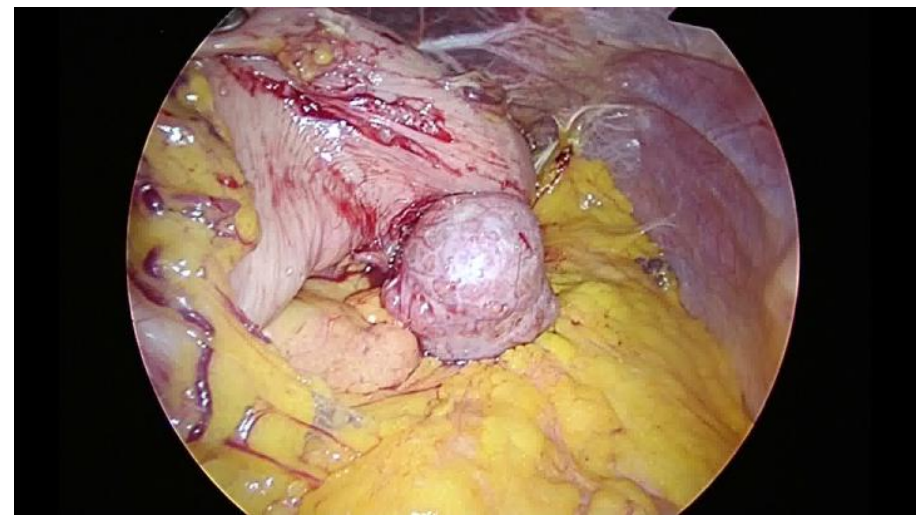

Fig 5: Visualization of Gastric GIST after division of short gastric vessels 


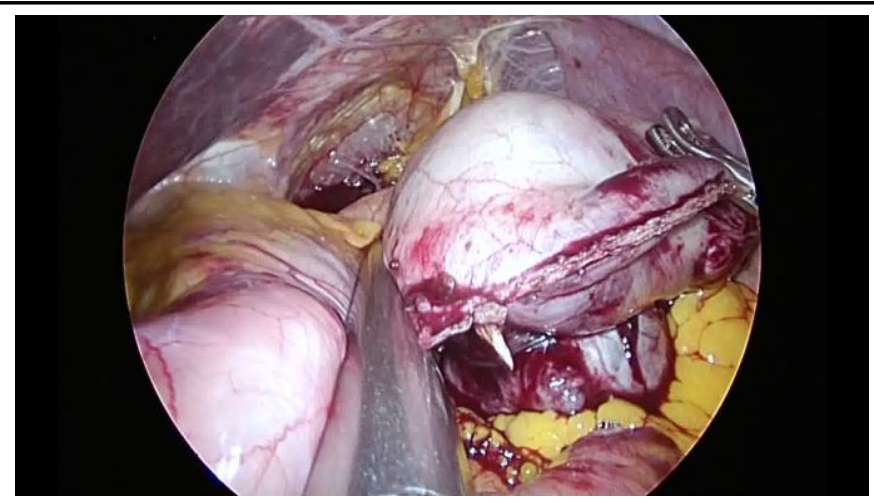

Fig 6: Wedge resection of gastric GIST after stapler firing

Table 8 Size of tumor and risk stratification

\begin{tabular}{|l|c|c|c|}
\hline $\mathbf{N}=\mathbf{1 8}$ & SIZE $(\mathbf{C M})$ & Mitotic count & Pathological risk stratification \\
\hline 6 & $2-5 \mathrm{~cm}$ & $<5 / 50 \mathrm{hpf}$ & Low \\
\hline 8 & $5-10 \mathrm{~cm}$ & $5-10 / 50 \mathrm{hpf}$ & Moderate \\
\hline 4 & $>10 \mathrm{~cm}$ & $(\mathrm{n}=2) 5-10 / 50 \mathrm{hpf}$ & Moderate \\
\hline & & $(\mathrm{n}=2)>10 / 50 \mathrm{hpf}$ & Severe \\
\hline
\end{tabular}

Table 9: Showed Ki prolification index and risk stratification

\begin{tabular}{|l|c|}
\hline K I - $\mathbf{6 7}$ Proliferation Index ( \%) & $\mathbf{N}=\mathbf{1 8}$ \\
\hline$<10$ & 14 \\
\hline$>10$ & 2 \\
\hline RISK STRATIFICATION & \\
\hline Low & 6 \\
\hline Moderate & 6 \\
\hline High & 4 \\
\hline
\end{tabular}

\section{Discussion}

2004, NCCN \& ESMO released consensus statements: laparoscopy be limited for GISTs $<2$ $\mathrm{cm}$ in size due to concerns of tumor rupture and seeding of the peritoneum and the ability to achieve an adequate oncologic margin. ${ }^{(1)} 2010$, NCCN updating their recommendations in their Task Force Report to include GISTs up to $5 \mathrm{~cm}$ as acceptable for laparoscopic resection. (2) Now, early studies focused on the laparoscopic techniques for the resection of large size GIST $(3,4,5)$ even at difficult anatomical locations ${ }^{(6,7)}$ and disease free interval following $\mathrm{R} 0$ resection ${ }^{(8)}$
In our study, Laparoscopic wedge resection, sleeve gastrectomy and partial gastrectomy $\mathrm{s}$ feasible in large size GIST $(8-11 \mathrm{~cm})$ and tumor located in posterior wall of stomach. Small size GIST near the GE Junction $(4-6 \mathrm{~cm})$ can be excised laparoscopically, but large size GIST > 8$10 \mathrm{~cm}$ may need conversion to open because of technical difficulties. Recurrence can occur in gastric GIST if tumor is high grade (Ki proliferation index $>10$ irrespective of location and size, and even after $\mathrm{R} 0$ resection) 


\section{Conclusion}

LAP is safe for large size GISTs. GISTs larger than $5 \mathrm{~cm}$ should not be a contraindication for laparoscopic tumor excision and may require open surgery.

\section{Acknowledgement: Nil}

Fund: Nil

\section{References}

1. Blay JY, Bonvalot S, Casali P, Choi H, Debiec-Richter M, Dei Tos AP, et al. Consensus meeting for the management of gastrointestinal stromal tumors. Report of the GIST Consensus Conference of 20-21 March 2004, under the auspices of ESMO. Ann Oncol. 2005;16:566-78.

2. Demetri GD, von Mehren M, antonescu CR, DeMatteo RP, Ganjoo KN, Maki RG, Pisters PW, Raut CP, Riedel RF, Schuetze S, Sundar HM, Trent JC, Wayne JD. NCCN Task Force report: update on the management of patients with gastrointestinal stromal tumors. J Natl Compr Canc Netw2010; 8 Suppl 2: S1S41; quiz S42-S44 [PMID: 20457867]

3. Vogelaere K. De, Van Loo I, Peters .O, Hoorens .A etal Laparoscopic resection of gastrointestinal stromal tumours (GIST) is safe and effective, irrespective of tumor size Surgical Endoscopy August 2012, Volume 26, Issue 8, pp 2339-2345

4. Marcelo de Paula, Rômulo ALMEIDIA, Christiano CLAUS , Eduardo BONIN, AntônioMoris VITAL etal Laparoscopic Resection Of Gastrointestinal Stromal Tumors (GIST) ABCD Arq Bras Cir Dig Original Article 2016;29(1):1-4.

5. Ye L, Wu X, Wu T, Wu Q, Liu Z, Liu C, et al. (2017) Meta-analysis of laparoscopic vs. open resection of gastric gastrointestinal stromal tumors. PLoSONE 12(5): e0177193
6. Jennifer, Pierce, Christopher, Hawkins, Matthews et al Laparoscopic gastric resection for gastrointestinal stromal tumors Surgical Endoscopy December 2008, Volume 22, Issue 12, pp 2583-2587.

7. Sanjoy, Sam, Bennet, Davies etal, Laparospic resection of Gastrointestinal stromal tumour Surgical Endoscopy Oct 2007, Vol 21, Issue 10 pp 1685- 1689

8. Kim, Nguyen etal Laparoscopic resection of gastrointestinal stromal tumors: Does laparoscopic surgery provide an adequate oncologic resection? World J Gastrointest Endosc2017 September 16; 9(9): 448-455. 